
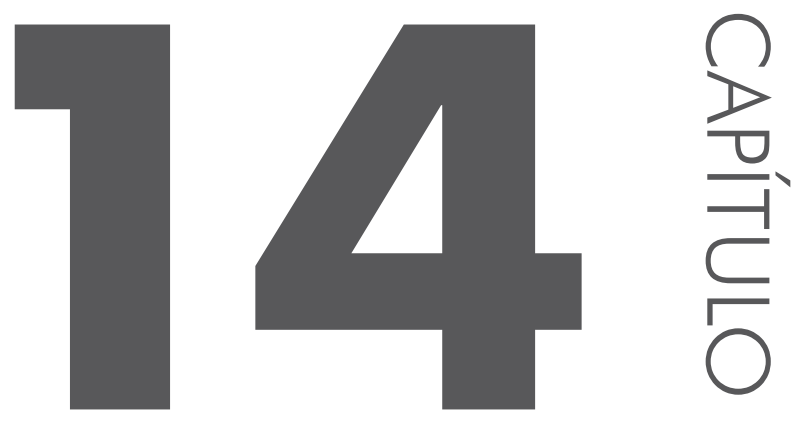

\title{
O FEMINISMO, AINDA
}

Simone Pereira Schmidt

\section{INTRODUC̣ÃO}

Para falar sobre o tema que me propus - a atualidade do feminismo dedico-me inicialmente a rever, como num filme de curta-metragem, alguns dos principais momentos que vivenciei nas últimas décadas. ${ }^{1}$ Em meu convívio com o feminismo, que remonta inicialmente ao século (e ao milênio!) passado, vivi a criação do movimento no Brasil, com suas bandeiras de luta vinculadas, nos anos 70 e 80 , às reivindicações da população por democracia e condições mínimas de sobrevivência e cidadania, alcançando depois a democracia e o lento processo de 'oficialização' do movimento, somado ao seu gradual e penoso ingresso no mundo da academia.

1 Uma versão anterior deste texto está publicada em KAMITA, Rosana C. e FONTES, Luísa C. (orgs). Mulher e Literatura: vozes consequentes. Florianópolis: Mulheres, 2015. p. 481-497. 
Nos anos 1990, com a era Collor, assistimos, perplexas e impotentes, ao que então parecia ser uma vitória definitiva do neoliberalismo, com seus discursos arrasadores contra toda uma cultura de esquerda construída ao longo de décadas, pela tenacidade dos movimentos sociais, de suas lutas e duras conquistas. Enfim, naqueles duros anos noventa parecia que o sonho (todos os sonhos que até então nos mobilizavam e davam sentido às novas vidas) tinha, literalmente, acabado. Numa grosseira metáfora do que considerava a rendição final do movimento feminista, o Caderno Mais! - suplemento cultural da Folha de São Paulo, que circulou nas décadas de 1990 e 2000 - de 8 de março de 1992 estampava, em sua capa, a imagem de duas pernas femininas, 'explicadas' pelo título: “O feminismo abre as pernas".

Nesse mesmo caderno cultural, na mesma época, vários temas que diziam respeito à cultura da 'nova esquerda', tais como feminismo, ecologia, sexualidade, diversidade cultural, etc., foram matéria de discussão, mas o tom desse debate, muitas vezes, era de descrença, ou ainda de desprezo em relação às bandeiras mais caras a esses movimentos, como a considerá-los temas resolvidos, ou simplesmente superados pelo 'trem da história'. O comentário a seguir, sobre a chegada dos primeiros debates sobre diversidade no país, exemplifica bem minha observação. O trecho a seguir é bastante ilustrativo:

quem, afinal, são eles? São os xiitas do multiculturalismo, do feminismo, do marxismo, do homossexualismo, pentelhos de todos os sexos e matizes, espantalhos involuntários do conservadorismo encastelado nas universidades e em outras instituições vitais ao metabolismo cultural da América... do Norte².

Como se não estivesse satisfeito com tamanha exibição de preconceito e xenofobia, o autor conclui seu artigo com uma espécie de exortação irônica, porém, acima de tudo, patética:

Prepare-se para quando a moda chegar aqui. Aproveite para gastar à vontade expressões como preto, crioulo, bola preta, nota preta, gelo baiano, programa de índio, judiar, bicha, etc. Elas podem estar com seus dias contados. Assim como o frango ao molho pardo.

Isso foi em 1992. De lá para cá, mais de vinte anos se passaram, e os 'pentelhos de todos os sexos e matizes', fizemos história, conquistamos espaço e visibilidade, alguns direitos, mas ironicamente, ainda escutamos 2 As citações foram extraídas do suplemento Mais!, e discutidas por mim, em maior profundidade em Schimdt (2000) 
essas vozes do passado com os mesmos discursos carregados de preconceito. Afinal, como não lembrar, ao reler as palavras do artigo de 1992, do debate presidencial no Brasil de 2014, quando discursos semelhantes, porém ainda mais virulentos, esbravejaram conclamando a população contra feministas, homossexuais, negros, índios?...

Recrudescem, no presente, manifestações de violento combate às conquistas que tivemos em todos esses anos. Recrudesce o enfrentamento porque avançamos, porque não estamos mais dentro do armário, ou debaixo do tapete, ou em qualquer beco escondido das cidades. Estamos no palco, dentro da arena, e não somos poucos.

Fiz essa breve incursão ao passado para chegar à questão que me propus, sobre as respostas que o feminismo tem a nos oferecer no momento atual. Minhas conclusões - de certo modo já antecipadas no título deste artigo - sinalizam não somente para sua atualidade, mas para seu caráter de extrema necessidade frente aos riscos sempre recolocados de retrocesso e perda de territórios. Mais do que necessidade, em última instância, o momento presente aponta para a urgência do feminismo, se considerarmos as profundas desigualdades com que não cessamos de nos deparar e a constante necessidade que temos de criar estratégias de enfrentamento. Se mergulharmos em direção à radicalidade política e epistemológica que é constitutiva do feminismo, podemos entendê-lo como resposta contundente aos desafios do presente.

No desenvolvimento do artigo, procurarei apontar aqueles que considero os principais temas construídos pelo feminismo nas últimas décadas, vistos na perspectiva dessa sua radicalidade produtiva. Ao enunciar esses temas em forma de algumas proposições ou enunciados, considero estar também esboçando os contornos dos principais desafios que as práticas feministas contemporâneas têm de enfrentar. Desafios que, a meu ver, são também nossos melhores instrumentos, afinados com o tempo presente. Inicio com uma frase emblemática do feminismo, essa casa materna de onde nascem os estudos de gênero, queer, LGBT e seus desdobramentos.

\subsection{O PRIVADO É POLÍTICO}

Com essa legenda, o feminismo dos anos 60-70 virou do avesso o senso comum que até então decretava que aquilo que acontecia na intimidade, na intimidade e no silêncio deviam permanecer. Em nome dessa 'privacidade' todos os segredos das famílias permaneciam ocultos, esposas sofriam em silêncio agressões e abandono, filhos e filhas reprimiam sua sexualida- 
de e tudo era vivido em segredo. Quase tudo era proibido. O feminismo propôs o rompimento definitivo dessa parede que ocultava o privado do público; bradou, nos anos 70, que quem ama não mata, e que lavar a honra conjugal com sangue não era direito do marido; pelo contrário, era uma barbárie cometida diariamente contra as mulheres.

A casa cujas paredes foram (e ainda estão) pouco a pouco se rompendo foi, tradicionalmente, como sabemos, um espaço feminino. Portanto, segundo a mesma hierarquia que pautava as desigualdades de gênero nos demais espaços da sociedade patriarcal, a dimensão íntima e privada da existência, a vida doméstica que acontecia entre quatro paredes, era considerada a menos importante, a menos nobre parte da vida, aquela que se revestia de considerável invisibilidade, e que não carecia de investimentos de qualquer ordem. O rompimento com essa divisão tradicional entre público/privado trouxe também a consequência de fazer valer para o mundo público aquilo que não tinha valor algum para a ordem pública, política, econômica, jurídica. Abriu-se, portanto, uma fenda nessa ordem, e dela emergiram novos sujeitos, até então considerados irrelevantes. Captando o espírito desse momento, Caetano Veloso disse numa canção, já faz algum tempo: "Enquanto os homens exercem seus podres poderes, índios e padres, negros, negros, bichas e mulheres, e adolescentes fazem o carnaval"3. É, portanto, a perspectiva dos subalternos, essa mesma perspectiva que hoje embasa grande parte dos estudos pós-coloniais e descoloniais, que se abre a partir do momento que as feministas declaram que o pessoal é político.

Outra contribuição dessa diluição de fronteiras entre público e privado foi a importante virada epistemológica que promoveu, trazendo também para o campo do conhecimento a proposta de dar visibilidade ao pequeno, ao subalterno, aos temas cotidianos e privados que supostamente não mereciam atenção da teoria. Assim o corpo, a casa, a cozinha, a comida, o quarto, as ervas, os rituais, os pequenos ritos, tudo se tornou passível de investigação, abandonando-se pouco a pouco as hierarquias de saberes, bem como do que deve ou merece ser estudado. E como o saber se aproximou bem mais da vida comum e cotidiana, tornou-se irrelevante a tradicional separação, tão cultuada, entre o sujeito e o objeto da pesquisa, outra hierarquia que assegurava ao investigador um alto posto de comando e de distanciamento impessoal e 'científico' em relação ao seu objeto. A partir dessa virada promovida pelo feminismo, sujeito e objeto de investigação se aproximam, se tocam sem medo de se contaminar; o sujeito sabe que é a paixão pelo seu objeto que o levará ao conhecimento mais profundo e mais verdadeiro. E tal como um Narciso a se debruçar sobre as águas, ele

3 A canção 'Podres poderes', de Caetano Veloso, integrou o álbum Velô, lançado em 1984. 
não sabe, mas suspeita, que no fim do caminho o encontro mais definitivo será com alguma parte de si mesmo.

\subsection{NÃO ESTAMOS MAIS EM CASA}

O grande pensador palestino Edward Said definiu nossa época como um tempo de exilados (SAID, 2003). Refugiados, expatriados, emigrados, cruzam fronteiras em todas as direções e vivem na pele a fratura incurável entre o eu e a terra natal. O lar.

Esse lar cada vez mais impalpável pode ser lido também como metáfora da nossa condição, de sujeitos errantes e desenraizados. Ao discutir a crise do sujeito moderno, que em séculos anteriores se acreditava uno, único, centrado e senhor de sua consciência, Stuart Hall (2003) aponta cinco movimentos fundamentais que promovem o descentramento desse sujeito, moldado pelo pensamento cartesiano. Desses cinco deslocamentos, quatro teriam sido operados, segundo Hall, por quatro pensadores decisivos: Marx, Freud, Saussure, Foucault. A sociedade, o inconsciente, a linguagem, o poder: instâncias nas quais a suposta estabilidade do sujeito se vê confrontada com sua incerteza, sua fugacidade e instabilidade. Um mundo, como disse Marx, onde tudo que é sólido desmancha no ar. O quinto deslocamento (adivinhem!) não é promovido por um pai-pensador, mas por um movimento e uma teoria, uma teoria construída a partir de um movimento político: o feminismo. Sim, é a partir do feminismo que nos vimos expulsos definitivamente da casa patriarcal, esse lugar onde reinou sozinho, por séculos, o sujeito moderno, racional, masculino, heterossexual, branco, ocidental.

E se não estamos mais em casa, é bem possível que nunca mais voltemos. Porque o lar, como nos ensinam Caren Kaplan e Inderpal Grewal, "tem sido muitas vezes um lugar marcado pelo sexismo e pelo racismo, um lugar que precisa ser retrabalhado politicamente, coletivamente”. É nesse sentido que autoras como Diana Brydon propõem uma teorização política e poética desse conceito móvel, instável e itinerante que é o lar - conceito disperso, avariado, diverso em nossos trabalhos atuais, como afirma o escritor Salman Rushdie ${ }^{4}$. A poetisa ganesa Abena Busia assim resume o impasse criado entre o sujeito e seu lugar de origem: "Nós podemos ir a qualquer lugar, menos para casa” (apud BRAIDOTTI, 2002, p. 12).

Essa perda do lar, se por um lado é marcada pela angústia das incertezas ao abandonarmos referenciais seguros em termos de crenças e pertencimentos, por outro, aponta para a possibilidade de reinvenção de seus 4 Os comentários e reflexões deste parágrafo, bem como a maior parte dos autores citados, me foram sugeridos pela leitura de dois artigos de Sandra ALMEIDA $(2011 ; 2012)$. 
significados emocionais, afetivos e políticos. O exílio, segundo Said, nos acena com suas fugidias promessas: ele é "a vida levada fora da ordem habitual (...) nômade, descentrada, contrapontística", e "assim que nos acostumamos a ela, sua força desestabilizadora entra em erupção novamente" (SAID, 2003, p. 60).

\subsection{COM A CASA NAS COSTAS}

E já que abandonamos a casa patriarcal e nos lançamos à rua, o mundo é agora a nossa casa. Em Borderlands/La frontera, Gloria Anzaldúa (1998) escreve: "Sou uma tartaruga, onde quer que eu vá, carrego o lar nas minhas costas". Fronteiras, viagens, bagagens, passagens. Viajantes, emigrantes, imigrantes. Marcas de etnias desconhecidas, países longínquos, códigos, convenções, regras, leis, costumes impressos nas mentes, nos corpos, marcados e interpretados em gênero, raça, geração, nacionalidade, religião.

A casa nas costas simboliza vidas em constante deslocamento. Como afirmou a teórica indiana Gayatri Spivak, "se o sujeito colonial era marcadamente um sujeito de classe e se o sujeito do pós-colonialismo é um sujeito racializado, então o sujeito da globalização é necessariamente gendrado" (apud ALMEIDA 2011, p. 243). Com esta declaração, Spivak chama nossa atenção para o importante papel desempenhado pelas mulheres, hoje, como sujeitos das diásporas contemporâneas, muitas vezes submetidas a violências específicas de gênero (tais como abusos sexuais, maternidade em situação precária, abortos clandestinos e sem assistência, migrações forçadas em situações de conflito, etc.), mas também, por outro lado, como sujeitos atuantes, agenciadoras de seus destinos e protagonistas de seus percursos. A fronteira cruzada torna-se, assim, um lugar de perigo e estranhamento, mas também, ao mesmo tempo, um lugar potencial de autotransformação e de agenciamento de novas identidades.

Deslocando o motif da viagem para o campo das possibilidades políticas, Rosi Braidotti (2002) encontra no conceito de nomadismo a síntese para o que considera a tarefa do feminismo contemporâneo. Para a teórica italiana, o "ser nômade", muito mais do que uma vida em viagem, significa uma subjetividade em permanente movimento de contestação:

As feministas - ou outros intelectuais críticos, como sujeitos nômades - são aquelas que têm uma consciência periférica; esqueceram de esquecer a injustiça e a pobreza simbólica: sua memória está ati- 
vada contra a corrente; elas desempenham uma rebelião de saberes subjugados. $\mathrm{O}$ estilo nômade tem a ver com transições e passagens, sem destinos pré-determinados ou terras natais perdidas. Assim, o nomadismo refere-se ao tipo de consciência crítica que resiste a se ajustar aos modos de pensamento e comportamento codificados. É a subversão do conjunto de convenções que define o estado nômade, não o ato literal de viajar (BRAIDOTTI, 2002, p. 10-11)

\subsection{NOSSOS CORPOS, NÓS MESMAS}

Se a casa em seu sentido material e simbólico se perde, em grande parte, no presente povoado pela ideia do trânsito, da viagem, da fronteira, do deslocamento, há entretanto uma dimensão irredutível da materialidade do sujeito que se desloca com ele, que lhe pertence e em lhe pertencendo, o define e constitui. Estou me referindo ao seu corpo.

Poucos temas têm ocupado tão decisivamente o centro da cena contemporânea como o corpo, pleno de significados para interpretar as demandas e as experiências do sujeito gendrado, racializado, localizado em suas múltiplas inscrições identitárias. Esse corpo, que podemos a princípio perceber como lugar de confluência de muitos discursos, tem sido identificado, descrito, de formas diversas: como mapa onde se traçam os percursos da história social e privada, relicário de memórias subjetivas, morada íntima do prazer e da dor, coleção de memórias, arena onde se travam embates de poder, locus onde se intersectam experiências pessoais e políticas, onde se travam conflitos advindos das identidades de gênero, classe, etnia, raça, sexualidade, nacionalidade, geração. Superfície em que se inscreve a violência, marcando indelevelmente o sujeito subjugado. Corpo subalterno, violado, domesticado. Corpo colonizado. Corpo subversivo, revolucionário. Lugar onde vive e se expressa a sexualidade: o desejo se manifesta, o sexo se concretiza, o erotismo pulsa. Corpos construídos, corpos desconstruídos. Corpo engendrado pelas tecnologias de gênero (Teresa de Lauretis), corpo-destino preso à imanência (Simone de Beauvoir), normatizado pela heterossexualidade compulsória (Adrienne Rich, Judith Butler). Corpos performáticos (Butler), desmontáveis (Donna Haraway), corpos que escapam a definições e regras (Foucault e seus intérpretes). "Tela de representação" do vivido (Stuart Hall) "capital cultural” (idem), casa que se carrega no exílio, nas viagens, nas diásporas e migrações (as feministas pós-coloniais), "local de inscrições sociais, políticas, culturais e geográficas" (Elizabeth Grosz, 2000, p. 47), enfim, como afirma Arthur Frank, “o feminismo nos ensinou que a história começa e termina com os corpos” 
(apud XAVIER, 2007)

Dentre os muitos paradigmas desconstruídos pelo feminismo, aqueles associados à experiência da corporalidade - resultando nas dicotomias norteadoras do nosso conhecimento, tais como os pares mente/corpo, espírito/matéria, onde se presume como certa a superioridade do primeiro termo sobre o segundo - abriram caminho para que se repensassem os outros binarismos que seguiam a mesma estrita lógica de poder. Desse modo o feminismo cumpriu (e vem cumprindo) importante papel na desconstrução de um mundo até bem pouco tempo decalcado sobre rígidas hierarquias que sedimentavam, de um lado, a superioridade do eixo onde se localizavam os princípios mente-espírito-alma-masculino-branco-ocidental; e do outro, corpo-matéria-sexo-feminino-não branco-não ocidental. Rompida a casa, o eixo, o centro, da casa se foi à rua, e da rua, ao mundo.

\subsection{NA RUA, NO MUNDO. E NÃO ESTAMOS SÓS}

É possível situar em torno dos anos 1980 a "crise de identidade" que acabou por romper em definitivo a expectativa de uma 'unidade' das mulheres em torno das reivindicações do movimento feminista.

É muito significativo que no início dessa década, em 1981, Gloria Anzaldúa tenha publicado sua conhecida carta às escritoras do terceiro mundo, em que deixa claro o tom reivindicativo de suas palavras: "é preciso uma enorme energia e coragem para não aquiescer, para não se render a uma definição de feminismo que ainda torna a maioria de nós invisíveis" (ANZALDÚA, 2000, p. 231). Ao manifestar-se dessa forma, Anzaldúa e suas companheiras estavam dando corpo a uma série de vozes que, juntamente com as suas, clamavam, então, pela ruptura de uma política de identidade que enclausurava o sujeito do feminismo dentro de uma norma hegemonicamente marcada em termos de raça, etnia e classe, situado, como até então tinha sido, numa posição de sujeito branco, ocidental, de classes economicamente privilegiadas.

A partir do choque provocado pela emergência de novos sujeitos na discussão teórica e política- tais como as "mulheres de cor radicais" como se autodefiniram Anzaldúa e suas companheiras, em especial as autoras da decisiva antologia de 1981, This brigde called my back (MORAGA; ANZALDÚA, 1981) -, as feministas negras e as ativistas do chamado terceiro mundo - e da contribuição das formulações pós-estruturalistas, que colocaram na ordem do dia a investigação em torno das relações existentes entre linguagem, subjetividade, organização social e poder - o feminismo passou a reformular seu conceito de identidade, abrindo-o a muitas 
possibilidades até então não contempladas, inclusive, e principalmente, aquelas experiências subjetivas em que se intersectam diferentes vetores identitários, tais como raça, gênero, classe, etnia, nacionalidade, etc. Para essa discussão, foi de grande importância, nos anos seguintes, a contribuição dos estudos pós-coloniais.

Estudiosas como Donna Haraway (1985), Teresa de Lauretis (1987), Judith Butler (1990) e Chandra Mohanty (1991) também encararam esse impasse, fazendo desse momento um importante turning point: das dificuldades iniciais em lidar com as diferenças entre as mulheres, teoria e práticas feministas passam a se ver diante da tarefa de lidar com tais diferenças, criando estratégias de negociação e políticas de coalizão, iniciativas que acabam por redefinir a própria noção de identidade, tornando-se elemento fulcral para o feminismo nas décadas seguintes. No âmago dessa concepção fraturada de identidade, que passa a ver o sujeito do feminismo não mais a partir de uma experiência única e sobredeterminada, encontra-se o conceito de interseccionalidade, o qual se torna uma importante ferramenta teórica para a redefinição desse sujeito. Na III Conferência Mundial contra o Racismo, ocorrida em Durban, África do Sul, em 2001, Kimberlé Crenshaw, estudiosa e militante afroamericana da questão legal feminista das mulheres negras, apresenta o conceito de interseccionalidade como elemento-chave para o estabelecimento de estratégias de empoderamento na luta das mulheres contra "o racismo, o patriarcalismo, a opressão de classe e outros sistemas discriminatórios”, os quais “criam desigualdades básicas que estruturam as posições relativas de mulheres, raças, etnias, classes e outras" definindo-o como um conceito "que busca capturar as conseqüências estruturais e dinâmicas da interação entre dois ou mais eixos da subordinação" (CRENSHAW, 2002, p. 177).

Se atentarmos mais especificamente para o contexto brasileiro, podemos comprovar que também entre nós a revisitação do conceito de interseccionalidade aponta para importantes contribuições à compreensão da história do país numa perspectiva feminista. Com escasso acesso ao ambiente acadêmico, mas fortemente vinculadas aos movimentos sociais, as feministas negras brasileiras tiveram que percorrer um caminho muito particular, de afirmação de sua presença em espaços onde não eram percebidas, além de se contrapor a algumas construções discursivas de grande poder em nossas cultura, tais como o mito da mestiçagem como fator de democracia racial e o elogio da mulata como elemento simbólico da "cordialidade", sexual e racial, sobre a qual se assentam tais discursos.

Em síntese, o feminismo das últimas duas décadas, conjugado aos estudos pós-coloniais, se lança no empreendimento de perceber as intersecções existentes entre gênero, raça e classe, categorias tão vivamente pre- 
sentes tanto no passado colonial quanto na história recente de um país como o Brasil, em que se mantêm estruturas de poder herdadas do 'modo português' de escrever a história colonial-patriarcal-escravocrata.

Podemos assim dizer que, por meio de ferramentas teórico-políticas como o conceito de interseccionalidade, o feminismo em perspectiva pós-colonial (ou descolonial, seguindo a contribuição de estudiosos latino-americanos que propõem esse conceito como alternativa ao que consideram um excessivo alargamento conceitual do pós-colonial, bem como um acento predominantemente 'anglocêntrico' em suas formulações, convocando-nos a 'desaprender' a razão imperial/colonial (cf. MIGNOLO, 2008, p. 290) em que nosso imaginário foi forjado) vem revelar algumas das complexas permanências da situação colonial no mapa das relações contemporâneas, especialmente no que se refere ao caráter sexualizado/ gendrado/racializado do sujeito feminino, periférico e subalterno. A opção descolonial - que denuncia as operações de exclusão, silenciamento e desempoderamento que estruturaram a vida social, política, e econômica e também o imaginário da chamada modernidade ocidental - atua no sentido de fazer soar algumas vozes que enunciam o que ficou por dizer; aquilo que povoa e apaga o silêncio de séculos.

\subsection{UM CAMINHO AO SUL}

O Sul apontado neste tópico não deve ser compreendido como um lugar geográfico, mas sim, como explica Boaventura de Sousa Santos, como "metáfora do sofrimento humano sistêmico e injusto provocado pelo capitalismo global e pelo colonialismo". O conjunto de esforços, epistemológicos e políticos reivindicados por Sousa Santos, tem por meta a construção de um cosmopolitismo subalterno, capaz de fazer frente a - e colocar-se como alternativa a - todo um processo histórico de construção do pensamento e do poder ocidental hegemônico, que determinou, segundo uma lógica estrita e abissal, a quem pertencia o direito ao saber, ao poder, ao transitar, ao dominar, conquistar, vencer. "Lutando contra a exclusão social, econômica, política e cultural gerada pela mais recente encarnação do capitalismo global, conhecida como "globalização neoliberal", como afirma Sousa Santos (2007, p. 83), o cosmopolitismo subalterno parte do reconhecimento de sua profunda incompletude, e busca, na intersecção entre os diferentes, a tradução dessas diferenças em propostas que se complementem, negociando suas distâncias, preenchendo suas faltas, acatando a incomensurabilidade daquilo que não pode ser traduzido. Trata-se de um aprendizado, não só em busca do que se precisa saber, mas também de desaprender. As epistemologias do Sul, em projetos emancipatórios que se 
articulam na prática tradutória, são ao meu ver um grande exemplo dos caminhos que podemos entrever como possibilidade para os estudos de gênero, em seu percurso nômade e contestador, descentrado, na fronteira, no exílio, e na intersecção. O outro, os outros, os próximos, nós.

\section{HAY QUE ENDURECERSE}

Por último, uma breve observação, que nos reconduz ao começo desta conversa. Che Guevara dizia, em sua célebre frase, que "Hay que endurecerse, pero sin perder la ternura jamás”. Em tempos mais recentes, eu diria, numa espécie de paródia (irônica porém reverente, como toda paródia), que temos sim que manter a ternura, mas sem deixar de nos endurecer, porque os tempos são duros. Tornamo-nos incomodamente visíveis e provocativos, nós, os excêntricos, as feministas, os queer, os negros, os indígenas. Nós, os doces bárbaros. Por isso nos tornamos também ameaça constante aos conservadores e retrógrados de toda espécie. Porque conquistamos visibilidade e alguma cidadania, mas ainda precisamos realizar muitas ações concretas: varrer das notícias diárias os crimes de violência especialmente contra mulheres e homossexuais, regulamentar as uniões afetivas entre todos os pares, através do casamento civil igualitário para quem o desejar, garantir direitos iguais de maternidade, paternidade, independentemente da orientação sexual e do estado civil dos pais, legalizar o aborto para estancar a morte cotidiana de mulheres em condição social precária, combater o racismo, a homofobia, a transfobia, o machismo, os preconceitos de toda ordem, concretos, simbólicos, falados, gritados, silenciosos. Punir a violência, educar para a paz.

É preciso realizar políticas de coalizão, projetos tradutórios com vistas a um cosmopolitismo subalterno, relações de vizinhança que ressignifiquem as redes verticais, construir poéticas e políticas de memórias que agreguem e representem o eu, os outros, os próximos ${ }^{5}$. É preciso reinventar o pessoal e o político, valorar e reinventar nossos corpos, nossos lares, assumindo a viagem, o exílio, a errância e o nomadismo como nossa condição. Acima de tudo, é preciso enunciar nossas identidades em trânsito, em contato, convívio e conflito, através de políticas e poéticas que celebrem o que somos, e a potência do que podemos ser. Porque enfim, como disse Bertold Brecht, é preciso mudar o mundo, e depois será preciso mudar o mundo mudado.

5 Utilizo aqui o conceito de 'próximos’ empregado por Paul Ricouer (2007). 


\section{REFERÊNCIAS}

ALMEIDA, Sandra Goulart. A África na diáspora; figurações do trânsito e cartografias de gênero em narrativas contemporâneas. In: FONSECA, Maria Nazareth; CURY, Maria Zilda (orgs.). África: dinâmicas culturais e literárias. Belo Horizonte: Editora PUCMinas, 2012.

ALMEIDA, Sandra Goulart. Exílios e diásporas: cartografias de gênero na contemporaneidade. In: RIAL, Carmen; PEDRO, Joana; AREND, Silvia (orgs.). Diásporas, mobilidades e migrações. Florianópolis: Mulheres, 2011. p. 229-256.

ANZALDÚA, Gloria [1981]. Falando em línguas: uma carta para as mulheres escritoras do terceiro mundo. Estudos Feministas, v.8, n.1, p. 229-236, 2000.

ANZALDÚA, Gloria [1987]. Borderlands/La frontera: The new mestiza. 40. ed. San Francisco: Aunt Lute Books, 2012.

BRAIDOTTI, Rosi. Diferença, diversidade e subjetividade nômade. Labrys, estudos feministas, n. 1-2, p. 1-16, 2002.

BUTLER, Judith [1990]. Problemas de gênero; feminismo e subversão da identidade. Rio de Janeiro: Civilização Brasileira, 2003.

CRENSHAW, Kimberlé. Documento para o encontro de especialistas em aspectos da discriminação racial relativos ao gênero. Estudos Feminista, v.10, n.1, p. 171188, 2002.

GROSZ, Elizabeth. Corpos reconfigurados. Cadernos Pagu, v. 14, p. 45-86, 2000. HALL, Stuart. A identidade cultural na pós-modernidade. 4.ed. Rio de Janeiro: DP\&A, 2000.

HARAWAY, Donna [1985]. Um manifesto para os cyborgs: ciência, tecnologia e feminismo socialista na década de 80. In: HOLLANDA, Heloísa Buarque de (org.). Tendências e impasses: o feminismo como crítica da cultura. Rio de Janeiro: Rocco, 1994. p. 243-288.

LAURETIS, Teresa de [1987]. A tecnologia do gênero. In: HOLLANDA, Heloísa Buarque de (org.). Tendências e impasses: o feminismo como crítica da cultura. Rio de Janeiro: Rocco, 1994. p. 206-242.

MIGNOLO, Walter. Desobediência epistêmica: a opção descolonial e o significado de identidade em política. Cadernos de Letras, n. 34, p. 287-324, 2008.

MOHANTY, Chandra Talpade [1991]. Under western eyes: feminist scholarship and colonial discourses. In: LEWIS, Reina and MILLS, Sara (eds.). Feminist postcolonial theory. Edinburgh: Edinburgh University Press, 2003. p. 49-74.

MORAGA, Cherrie; ANZALDÚA, Gloria (eds). This bridge called my back: writings by radical women of color. New York: Kitchen Table - Women of Color Press, 1983. 
RICOEUR, Paul. Memória pessoal, memória coletiva. In: RICOEUR, Paul. A memória, a história, o esquecimento. Campinas: Editora da UNICAMP, 2007. p. 105-142.

SAID, Edward. Reflexões sobre o exílio e outros ensaios. São Paulo: Companhia das Letras, 2003.

SANTOS, Boaventura de Sousa. Para além do pensamento abissal: das linhas globais a uma ecologia de saberes. Novos Estudos CEBRAP, n. 79, p. 71-94, 2007.

SCHMIDT, Simone Pereira. O feminismo nas páginas dos jornais: revisitando o Brasil dos anos 70 aos 90. Estudos Feministas, v. 8, n. 2, p. 77-88, 2000.

XAVIER, Elódia. Que corpo é esse? O corpo no imaginário feminino. Florianópolis: Mulheres, 2007. 
